\title{
HISTORY AND FUTURE OF THE MINNESOTA KARST FEATURE DATABASE
}

Tipping, Robert G.

University of Minnesota, Minnesota Geological Survey, 2609 Territorial Road, St. Paul, Minnesota, 55114, USA, tippi001@umn.edu

Rantala, Mathew

University of Minnesota, Minnesota Geological Survey, 2609 Territorial Road, St. Paul, Minnesota, 55114, USA, mjrantal@umn.edu

Alexander, E. Calvin Jr.

University of Minnesota, Department of Earth Sciences, 310 Pillsbury Drive SE, Minneapolis, Minnesota, 55455, USA, alexa001@umn.edu

Gao, Yongli

Center for Water Research, Department of Geological Sciences, University of Texas, San Antonio Department of Geological Sciences, One UTSA Circle, San Antonio, Texas 78249, USA, yongli.gao@utsa.edu

\section{Green, Jeffrey A.}

Minnesota Department of Natural Resources, Ecological and Water Resources, Rochester Office, 3555 9th Street NW, Suite 350, Rochester Minnesota, 55901,USA, Jeff.green@state.mn.us

\begin{abstract}
Since the 1990s the University of Minnesota and the Minnesota Department of Natural Resources have maintained a karst features database that is used to conduct research on karst processes and inventory karst features. Originally designed as a tabular database only, the karst features database developed into a spatial database in 2002 with tabular data stored in Microsoft Access and a spatial component managed in ESRI ArcView. In 2012 the database was converted to a single, relational database platform, PostgreSQL, with both tabular and spatial components edited in ESRI ArcMap. Custom editing forms are written in Visual Basic and are accessed in ArcMap sessions by ESRI add-ins. The current database infrastructure allows for remote editing. Read-only versions of the data are available in GIS/spatial format for public use via web services. Future development plans include links to water chemistry data, water level measurements, and other ancillary data; along with the addition of vectors to represent dye traces and polygons for larger karst features.
\end{abstract}

\section{Introduction}

Karst is recognized as a term describing both distinct landscapes - karst terrains - and distinctive hydrology related to the movement of water in soluble bedrock karst processes. The construction of a karst features database that adequately documents both karst terrains and karst processes for researchers, regulators, and planners is a formidable task. How do uses and potential abuses impact database design and content? What should be in such a database? How does data get in, or out? While the Minnesota Karst Features Database (KFD) has been primarily research oriented, these broader questions have guided past and current database development and will continue to guide development going forward. This paper documents the history and future of the KFD, with the goal of providing the reader a better understanding of how it came to be and where it is going.

\section{History and Methods}

The Minnesota Speleological Survey created the database in the early 1970s as a sinkhole inventory. Sinkhole locations were collected on 4-by-6 inch index cards with unique identifiers, and plotted on 1:24,000-scale USGS 7.5-minute topographic maps (Alexander, 2015). About one hundred sinkholes were mapped in this manner, and this process continued into the early 1980s. Many sinkholes in Minnesota, especially those several meters or less in diameter, are ephemeral features that appear in fields and are filled, if possible, to minimize disruption of agricultural practices.

As personal computers and spreadsheet software became available in the 1980s the evolution towards fully functional geographic information systems (GIS) man- 
agement of karst features data began. The first targeted sinkhole inventory for a specific Minnesota county was begun during that timeframe (Dalgleish and Alexander, 1984). The Winona County sinkhole inventory involved a systematic survey of landowners across the county. Basic location information was recorded for each sinkhole such as who found it, how and when it was found, along with some estimate, if known, of when the sinkhole first appeared. Sinkhole physical attributes were recorded, including width and depth and morphology (steep-walled or shallow-walled). Sinkhole contents were also recorded.

A total of 535 sinkholes in Winona County were mapped in this manner, each with their own unique identifier; many filled sinkholes were also reported. Data collected in 3-ring binders were later entered into fixed-format text for keypunch services and then loaded into single text files with Fortran-based retrieval and reporting capabilities (Figure 1). Sinkhole locations were digitized and stored on a main-frame computer at the University of Minnesota; allowing sinkhole distributions to be plotted and a limited number of sinkhole attributes to be displayed in map form. Formatted text records were eventually transferred to personal computer spreadsheet software.
By the mid-1980s the field-based sinkhole inventory combined with geologic mapping led to two regional observations (the first self-apparent but not documented in map form): 1) sinkholes occur where the landscape is underlain by soluble carbonate rock; 2) sinkholes occur where the bedrock is covered with less than 50 feet of sediment. Both trends were displayed as an unpublished, first-generation regional map of Minnesota Karst Lands in 1992 (Alexander, 2015; Figure 2).

In 1995 the distribution of sinkholes in Winona County Minnesota was revisited (Magdalene, 1995). Locations were digitized, and data were managed in a Microsoft Excel spreadsheet. Six hundred fourteen sinkholes were mapped, including 34 new and 39 previously unreported sinkholes. Sinkhole attributes from the earlier table structure were reviewed and refined. Combining the KFD and geologic mapping as part of the County Geologic Atlas Program Magdalene showed that sinkholes are clustered. In addition, higher densities of sinkhole occurrence were linked to a specific bedrock stratigraphic position - the contact between the Oneota Dolomite and Shakopee Formation within the Prairie du Chien Group.
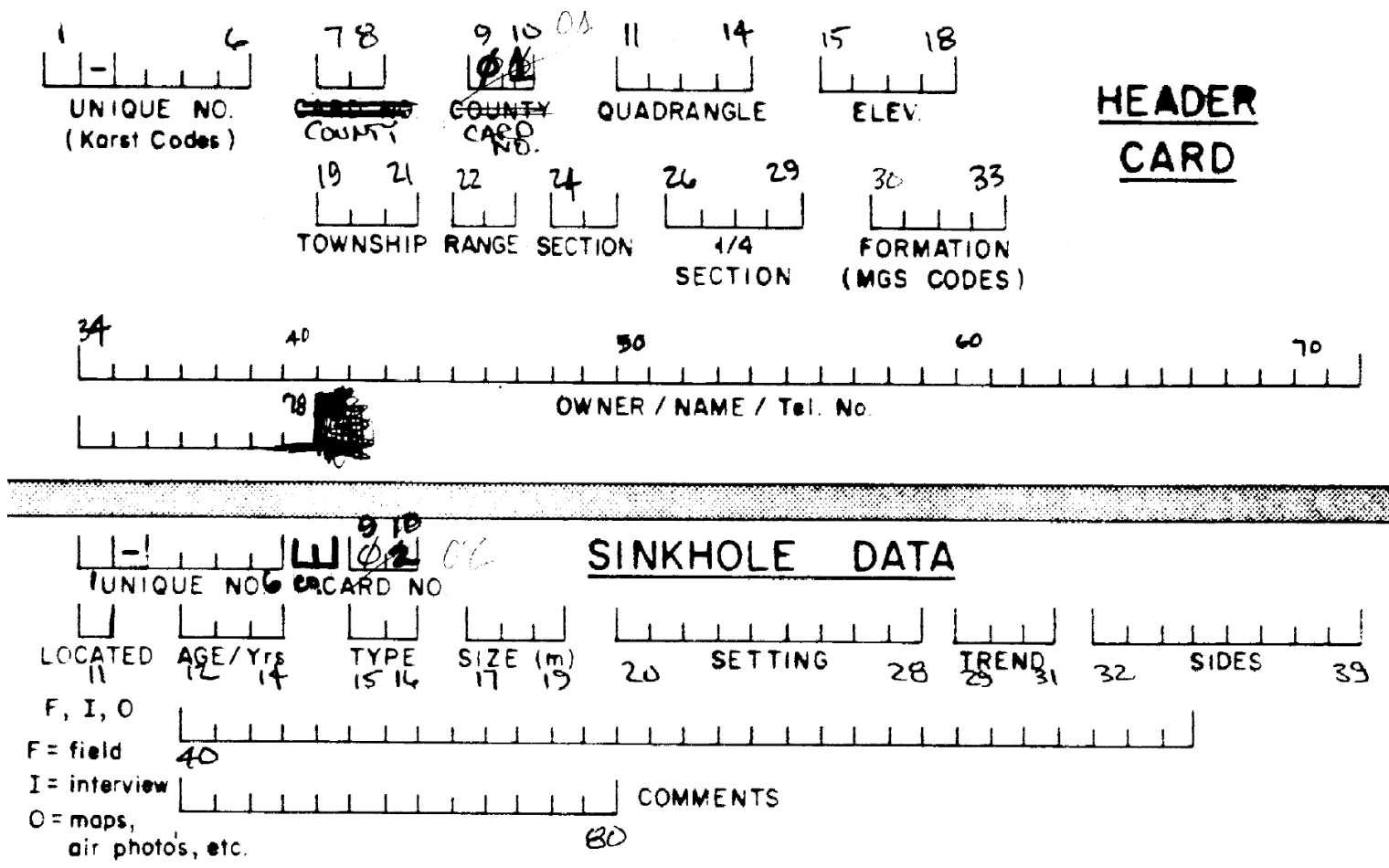

Figure 1. Early sinkhole data keypunch form, Karst Features Database, 1980s (provided courtesy of T.E. Wahl). 


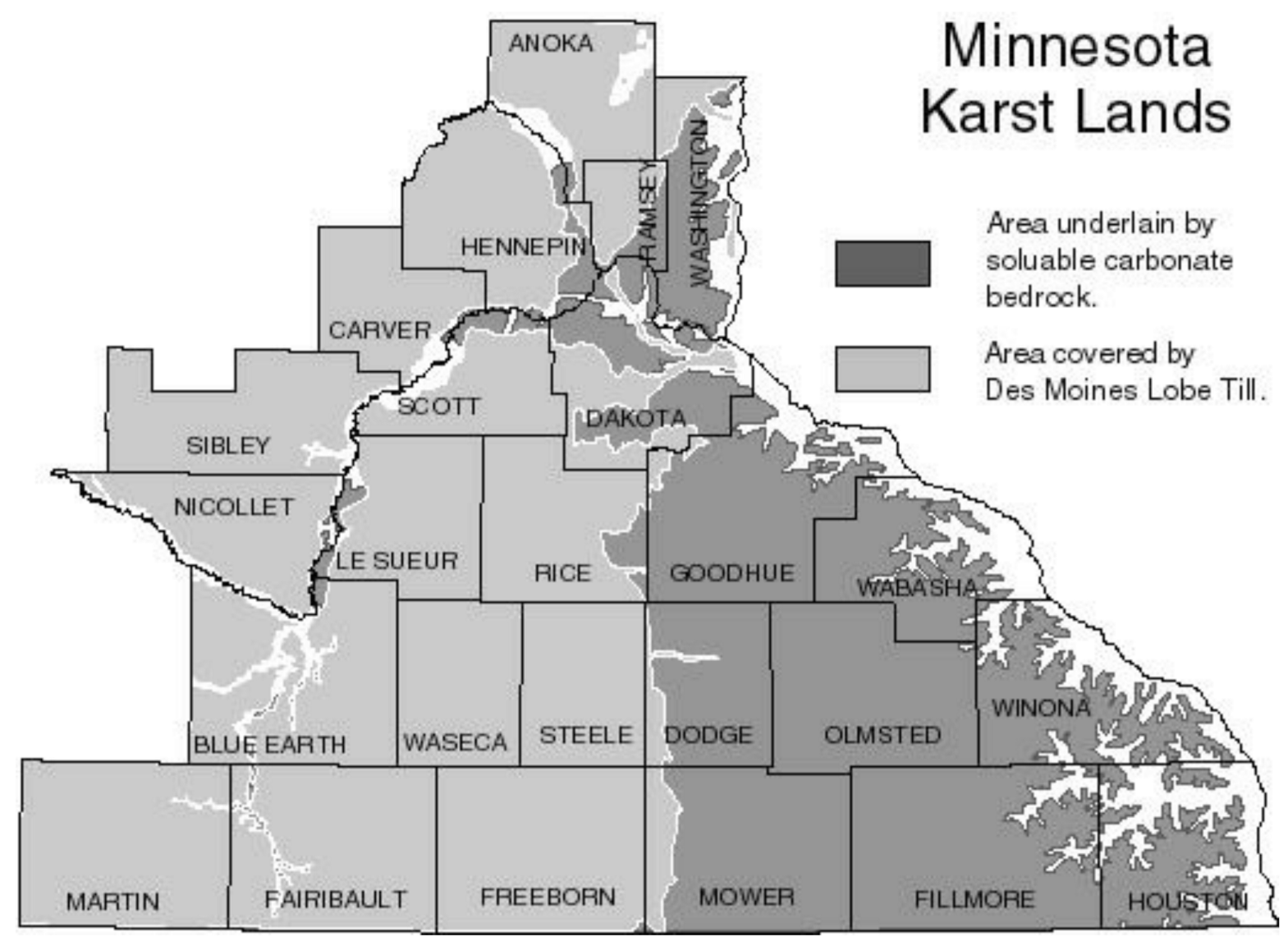

Figure 2. Minnesota Karst Lands map, 1992 (Alexander, 2015).

By that time, GIS software for personal computers, PC ARC/INFO (ESRI, 1987), was fully in use in Minnesota for resource mapping. A county geologic atlas project had just begun in Fillmore County, where sinkholes and springs occur in greater concentration than anywhere else in the state. Karst features mapping, which had focused largely on sinkholes, now expanded to include springs. Springshed mapping, based on dye trace results, had already been underway for a number of years, and the KFD became the primary database for managing dye input and output locations and compiling groundwater flow routes to identify springshed boundaries.

Many of the sinkholes in Fillmore County are large enough to be visible on 1:24,000 USGS 7.5 minute topographic maps. Points were added to the KFD by digitizing closed depressions on the maps. This process captured features with a minimum size (width) of approximately 25 meters. Points were also added from the 1951 Fillmore County Soil Survey. Combined, these two sources added approximately 4,000 sinkholes to the KFD. Sinkhole distributions and depth-to-bedrock data, searchable in a GIS environment, were used to create a sinkhole probability map of the county (Alexander et al., 1995). Attribute tables were developed for springs and newly acquired and historic spring data were added to the KFD.

The period of 1998 to 2003 saw advances in spatial data technology, including the incorporation of global positioning system (GPS) equipment in standard fieldwork and increased accessibility of geospatial data, such as current and historic aerial photos. The development of ArcView for personal computers, along with its scripting language Avenue facilitated the development of custom user interface forms for data entry and editing and supported the automation of geoprocessing for more complex spatial analysis. During this period, sinkhole locations and depth-to-bedrock data were used to create a sinkhole probability map for Goodhue County (Alexander et al., 2003); digital elevation models of bedrock stratigraphic units were used to assign stratigraphic positions for sinkholes and springs in Wabasha County (Tipping et al., 2001); the KFD expanded beyond south- 
eastern Minnesota to document sinkholes and springs in the sandstone of Pine County Minnesota (Shade, 2002); karst terrain was mapped in distinct units in Mower County based on surface and subsurface drainage characteristics, bedrock geology, depth to bedrock and land surface topography (Green et al., 2002a; 2002b). In all instances, the KFD was used to inventory new features and sinkholes that are now filled using historic aerial photos and soil surveys.

The greatest expansion of the KFD occurred during the period of 2003 to 2005 when funding became available to conduct regional karst investigations and concurrent database development, resulting in a fully functional karst features database (Gao and Alexander 2003; Gao et al., 2002; 2005a; 2005b; 2005c; Gao, 2008). The project formalized the database structure, code tables, and metadata that are currently in use. A combination of ArcView and Microsoft Access platforms were used, with location information stored in ArcView shape-files and attribute information stored in tables within an Access relational database. Custom user forms were developed for entering and editing data, along with report writing capability.

The project proposed structures for database features not yet implemented, including dye trace vectors and poly- gons to delineate karst features over large areas, such as sinkhole clusters. The project also proposed conceptual models for future database use including: spatial analysis; data mining; geostatistical analysis and descriptive analysis; and hydrogeologic analysis such as springshed delineation and springshed water budgets.

Several regional analyses were conducted by Gao (2002) to demonstrate the KFD as a research tool. Nearest neighbor analyses were used to show that sinkholes change from clustered to random to regular by scale, direction, and geologic unit (Gao et al., 2005a). Decision tree and cartographic tools were developed to create sinkhole probability maps for five southeastern Minnesota Counties (Gao and Alexander, 2008). A new map was created that included transition karst defined by depth to carbonate bedrock (Figure 3, Gao et al., 2008). This map was based on more detailed geologic mapping than was available for the first Karst Land Map (Figure 2).

In 2012, the database was converted to a single, relational database platform-PostgreSQL-with tabular and spatial components edited in ESRI ArcMap. Custom editing forms were written in Visual Basic and they are accessed in ArcMap sessions as ESRI add-ins. The

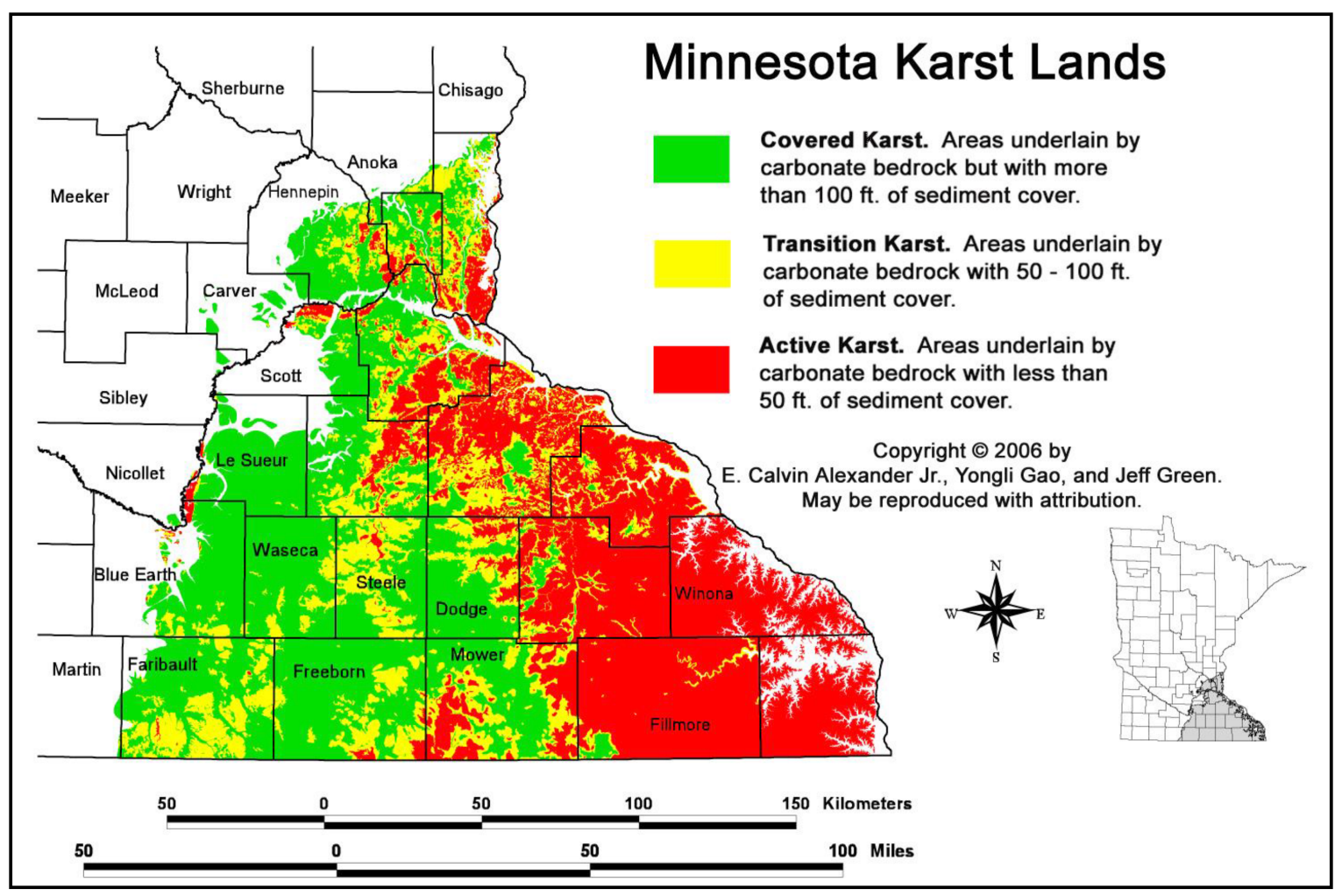

Figure 3. Minnesota Karst Lands map, 2006 (Alexander, 2015; Gao and Alexander, 2008) 
current database infrastructure allows for remote editing. Read-only versions of the data are available in GIS/spatial format for public use via web services.

\section{Concurrent Karst Research and Future of the KFD}

Throughout the past forty years, karst research in Minnesota has included dye tracing, cave exploration, speleothem dating, spring temperature monitoring, and geohazards investigations. Remediation investigations addressed tanker spill sites, fuel refineries, spring water quality, and structural (geotechnical) integrity. Regional investigations have taken place to evaluate geologic controls on groundwater flow and karst development. In all cases the KFD has played an important role in characterizing current and past hydrologic conditions in Minnesota karst terrain.

As the database expands and more users become acquainted with its use data standards, access, and main-

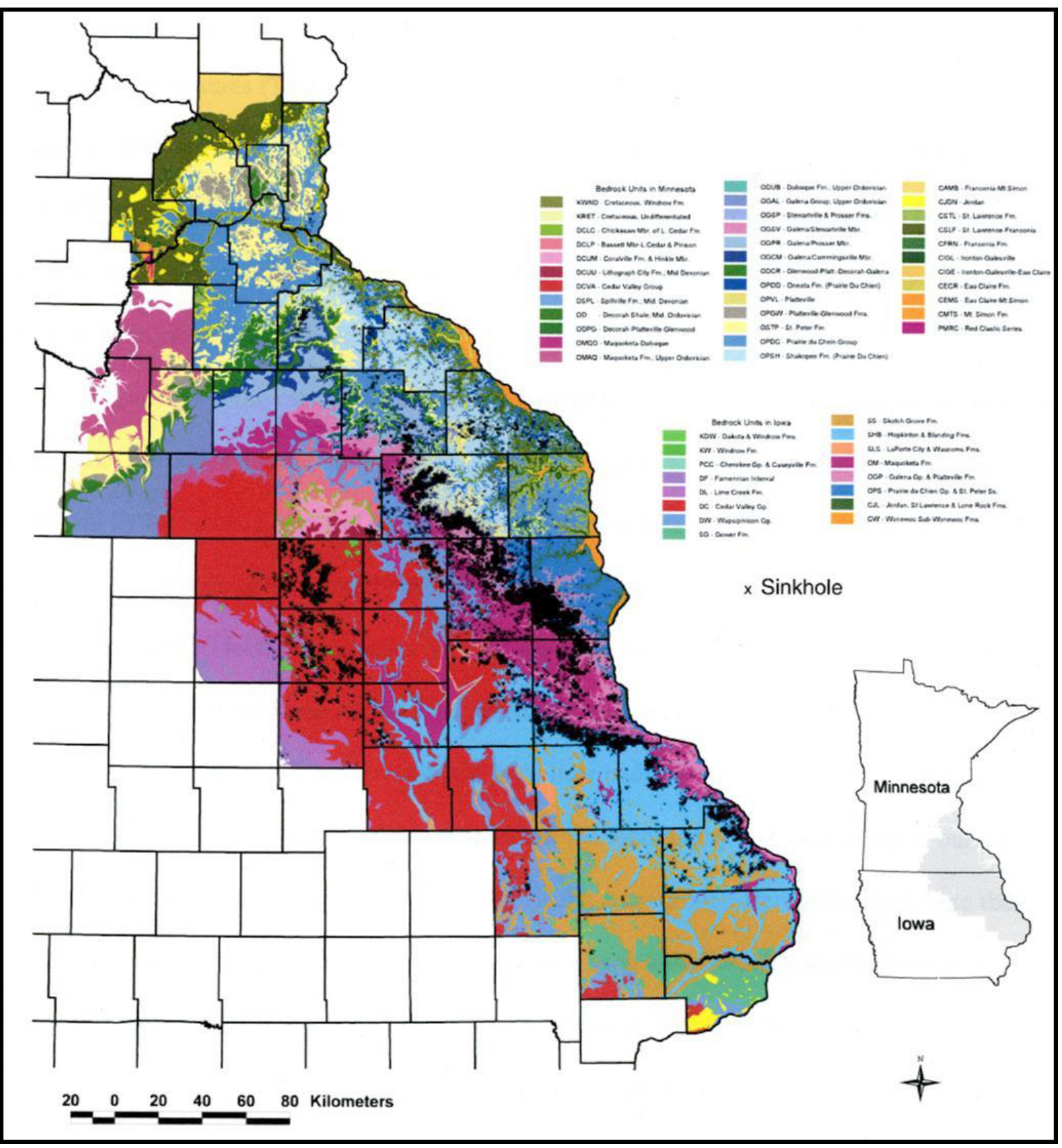

Figure 4. Sinkhole distribution and bedrock geology, Minnesota and lowa. (Gao et al., 2005a) 
tenance issues become more critical. Combining data across state boundaries is possible without merging databases, but doing so requires clear metadata describing field names and definitions (Figure 4).

The focus of the database thus far has been on locations of sinkholes and springs. LiDAR data availability in Minnesota has greatly expanded the inventory of karst features at the land surface, particularly in wooded areas where inventories had been difficult and limited (Figure 5). LiDAR has also been used for landscape analysis, including identification of losing streams. LiDAR also provides remarkable elevation control-approximately 0.2 meter vertical resolution - critical for investigating relationships between karst terrain and hydrologic systems.
Future development plans include more focus on subsurface flow conditions. As proposed by Gao (2002), line features depicting dye trace vectors could be added, as well as polygon features showing springshed areas. Conduit information has also been proposed (Gao, 2002). How would this be recorded spatially? Outcrop occurrence is one possibility where conduit location, elevation, and stratigraphic position would be recorded as a karst feature. Hydraulically active fractures and conduits in boreholes could also be recorded by location, elevation, and stratigraphic position. Descriptive attributes of conduits could also be added, such as dimensions, or flux carrying capacity. Matrix and fracture hydraulic conductivity could also be recorded.

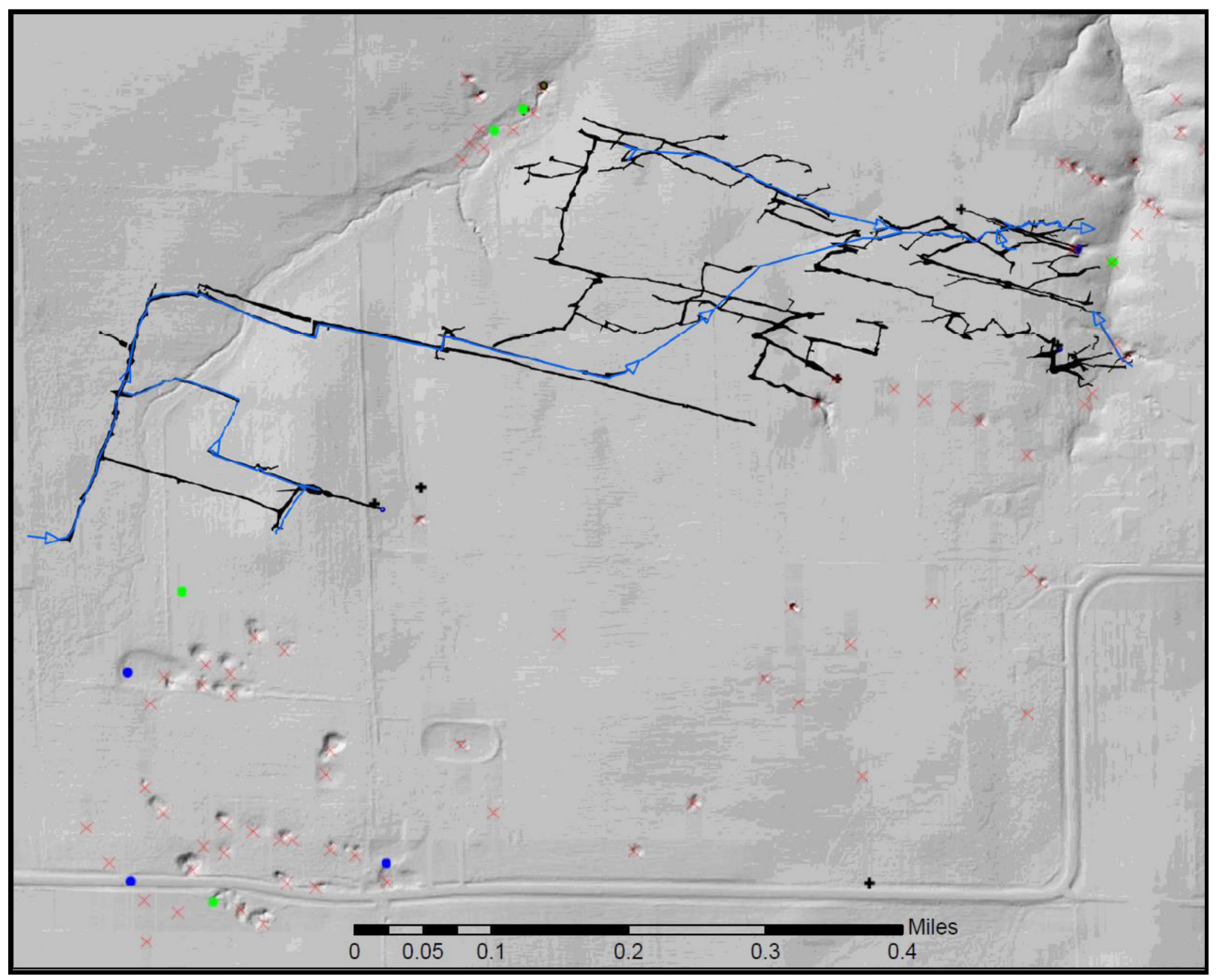

Figure 5. LiDAR hillshade data used to identify karst features, along with overlay of Spring Valley Caverns, Minnesota cave survey. Heavy black lines are air-filled cave passages; blue lines are underground streams; red " $x$ "s are sinkholes, blue dots are springs; green dots are stream sinks; black "+"s are cave entrances and other surface features. (Alexander, 2015). 
Dataloggers provide critical information for understanding the temporal variability of karst groundwater flow. Such high-resolution data should be incorporated as one-to-many data relationships associated with various points within karst flow systems. Measurements can include temperature, conductivity, and flow, as well as any other parameters for which probes and transducers are developed. Having unique identifiers for each karst feature allows points to be associated with other datasets, including water chemistry and isotopic data being stored elsewhere.

Ideally, the KFD describes and documents both karst terrain and karst processes. As described in this paper, the visibility of sinkholes has traditionally been the focus of karst feature databases. These points, however, do not adequately describe karst "plumbing" that is often the focus of karst research and remediation investigations.

\section{References}

Alexander EC Jr. 2015. Development of the Minnesota karst Features data base, 1970s to the Future. [Internet] 8th Annual Driftless Area Symposium. February 3rd and 4th, 2015, Radisson Hotel, LaCrosse, Wisconsin. [cited 2015 February 25]. Available from: (http://www.darestoration.com/ Symposium.html, accessed 2/25/2015)

Alexander EC Jr, Green JA, Alexander SC, Spong RC. 1995. Springsheds. Plate 9 of 9, Geologic Atlas of Fillmore County, Minnesota, County Geologic Atlas Series C-8, Part B, Minnesota Department of Natural Resources. scale 1:100,000.

Alexander EC Jr, Berner DJ, Gao Y, Green JA, Alexander SC. 2003. Sinkholes, sinkhole probability, and springs and seeps. Plate 10 of 10, Geologic Atlas of Goodhue County, Minnesota, County Geologic Atlas Series C-12, Part B, Minnesota Department of Natural Resources. scale 1:100,000.

Dalgleish JB, Alexander EC Jr. 1984. Sinkholes and sinkhole probability. Plate 5 of 8 , Geologic Atlas of Winona County, Minnesota, County Geologic Atlas Series C-2, Minnesota Geological Survey. scale 1:100,000.

ESRI. 1987. PC ArcInfo: Geographical Information system software for personal computers. Redlands, CA.

Gao Y. 2002. Karst feature distribution in southeastern Minnesota: Extending GIS-based database for spatial analysis and resource management [Ph.D. thesis]. Minneapolis (MN): University of Minnesota. 229 p.

Gao Y, Alexander EC Jr, Tipping RG. 2002. The development of a karst feature database for southeastern Minnesota. Journal of Cave and Karst Studies 64 (1): 51-57.

Gao Y, Tipping RG, Alexander EC Jr. 2006. Applications of GIS and database technologies to manage a karst feature database. Journal of Cave and Karst Studies 68 (3): 144-152.

Gao Y, Alexander EC Jr. 2003. A mathematical model for a sinkhole probability map in Fillmore County, Minnesota. In: Beck BF (editor) Sinkholes and the engineering and environmental impacts of karst. Proceedings of the 9th multidisciplinary conference. Huntsville, Alabama, September 6-10, ASCE Geotechnical special publication, no. 122, p. 439-449.

Gao Y, Alexander EC Jr, Barnes RJ. 2005a. Karst database implementation in Minnesota: Analysis of sinkhole distribution. Environmental Geology 47 (8): 1083-1098.

Gao Y, Alexander EC Jr, Bounk M, Tipping RG. 2005b. Metadata development for a multi-state karst feature database. In: Beck BF (editor) Sinkholes and the engineering and environmental impacts of karst. Proceedings of the 10th multidisciplinary conference. San Antonio, Texas, September 24-28, ASCE Geotechnical special publication, no. 144, p. 629-638.

Gao Y, Alexander EC Jr., Tipping, RG. 2005c. Karst database development. Design and data assembly of karst features in Minnesota. Environmental Geology 47 (8): 1072-1082.

Gao Y, 2008. Spatial operations in a GIS-based karst feature database. Environmental Geology 54 (5): 1017-1027.

Gao Y, Alexander EC Jr, 2008. Sinkhole hazard assessment in Minnesota using a decision tree model. Environmental Geology 54 (5): 945-956.

Green JA, Marken WJ, Alexander EC, Jr., Alexander SC. 2002a. Karst unit mapping using geographic information system technology, Mower County, Minnesota, USA. Environmental Geology 42 (5): 457-461.

Green JA, Alexander EC, Jr, Marken WJ, Alexander SC. 2002b. Karst hydromorphic units. plate 10 of 10, Geologic Atlas of Mower County, Minnesota, County Geologic Atlas Series C-11, Part B, Minnesota Department of Natural Resources. scale $1: 100,000$.

Magdalene SC. 1995. Sinkhole distribution in Winona County, Minnesota, revisited. [Thesis] University of Minnesota. $205 \mathrm{p}$.

Magdalene SC, Alexander EC Jr. 1995. Sinkhole distribution in Winona County, Minnesota revisited. In: Beck BF, Person FM (editors) 
Karst Geohazards: Proceedings of the Fifth Multidisciplinary Conference on Sinkholes and the Engineering and Environmental Impact of Karst. Gatlinburg, Tenn., 2-5 April, A.A. Balkema, Rotterdam, p. 43-51.

Shade BL. 2002. The genesis and hydrogeology of a sandstone karst in Pine County. [Thesis] University of Minnesota: $171 \mathrm{p}$.

Tipping RG, Green JA, Alexander EC Jr. 2001. Karst features. plate 5 of 7, Geologic Atlas of Wabasha County, Minnesota, County Geologic Atlas Series C-14, Part A., Minnesota Geological Survey. scale $1: 100,000$. 